\title{
Towards a Holistic Sustainability Evaluation for Transport Alternatives
}

\author{
By Thu Trang Nguyen ${ }^{1}$, Helmut Brunner ${ }^{1}$, Mario Hirz ${ }^{1}$
}

\begin{abstract}
The transport sector is responsible for a broad range of ecologic impacts, e.g., energy consumption, greenhouse gas emission or air pollution. It is therefore highly important to assess transport solutions in terms of their sustainability. Widely used approaches for sustainability analysis in the transport sector include life cycle assessment (LCA), economic approach, multi-criteria decision analysis (MDCA), and assessments based on indicators. In practice, these approaches consist of several methods, i.e., product-based LCA, fleet-based LCA, cost benefit analysis (CBA), cost effectiveness analysis (CEA), value measurement MDCA, ideal-solution based MDCA, outranking MDCA, and indicator-based assessment. Even though there is a larger number of assessment methods, a holistic framework for sustainability evaluation of different transport solutions is still missing. Selection of suitable assessment methods depends on a vast array of factors. This paper proposes to utilise "application levels" for the selection process. Firstly, the paper provides an analysis of the application levels of the common assessment methods and evaluation criteria within the transport sector based on a literature review. The application levels are illustrated by identifying two dimensions, namely system level and decision-making level, ranging from Low to High. Afterwards, a six-step framework for a holistic evaluation of transport alternatives is proposed.
\end{abstract}

Keywords: sustainability assessment, economic approach, indicator-based assessment, life cycle assessment, multicriteria decision analysis, sustainable transport

\section{Introduction}

Transport sector is one of the main energy consumers, responsible for $27 \%$ of final energy consumption globally (IEA, 2017), respectively 31\% in Europe (eurostat, 2019). The transport sector causes significant environmental impacts such as greenhouse gas emissions (GHG) and air pollutants. To be specific, about 14\% of global GHG emission comes from transport activities (IPCC, 2014). In 2017, total annual global GHG emissions reached a record high of 53.5 GtCO2e (UNEP, 2018). It is reported that in this same year, $27 \%$ of total EU-28 GHG emissions were caused by the transport sector. Of which, road transport is responsible for $72 \%$ of GHG emissions (EEA, 2019). Predictions show that emissions from the transport sector might increase by $100 \%$ by 2050, if no suitable corrective measures will be applied (IPCC, 2014).

Therefore, mitigation and reduction of energy use and environmental impacts of transport, especially road transport, are critical to achieve a more sustainable mobility in the future. For the past decade, more and more technology advancements, innovative management methods and new business models have been introduced in the field, e.g., alternative propulsion systems, innovative vehicle concepts, connected vehicles, autonomous driving, technology advances in micro mobility (e.g., e-bikes and e- 
scooters), shared mobility approaches or multi-modal mobility concepts. In order to make the transport sector more sustainable, current efforts focus on these topics: technological improvements (i.e., improvement in efficiency of the transport process and introduction of new technologies), modal shifts (i.e., promotion of more energy efficient and environment friendly transport modes such as walking, cycling, public transport), changing driving behaviours, and reduction of transport demand (Messagie, et al., 2010) (UNESCAP, 2015). In the long term, an international integrated intermodal transport and logistic system is expected to develop, aiming at optimizing the needs for transporting goods and passengers, minimizing resource consumption as well as the adverse social impacts created by transport operations, and generating low emissions (UNESCAP, 2015).

It has been becoming highly complicated to evaluate sustainable transport options considering multi-dimensional needs of passengers, goods transporters, mobility providers and decision makers at once, especially with regards to urban mobility planning, where many political actors and stakeholders are involved in the decision process (Longo, Medeossi, \& Padoano, 2015). Several approaches have been applied in order to evaluate sustainability aspects of transport projects and systems. (Awasthi, Omrani, \& Gerber, 2018) classifies the popular approaches for sustainability evaluation of mobility projects into life cycle assessment (LCA), cost benefit analysis (CBA) and cost effectiveness analysis (CEA), assessment indicator models, and multi-criteria decision analysis (MCDA). These approaches attempt to take into account the complex criteria matrix in terms of technological, social, environmental and economic aspects based on which transport alternatives will be assessed.

However, so far most of the existing literature in this domain only introduce a certain methodology or apply one or a few approaches for an analysis. As a result of a literature survey, it is visible that the applied methods lack a comprehensive evaluation of sustainability of different transport solutions and the indication of their appropriate application level. Since no tool is appropriate for every problem (Field, Kirchain, \& Clark, 2000), if the methods are mapped according to their application level, i.e., system level and decision making level, it will be possible to select more suitable methods to assess transport alternatives based on their expected impact and evaluation criteria.

In addition, a holistic approach for sustainability evaluation of mobility solutions for both passenger and goods transport is still missing. Traditional LCA meets with difficulties in assessing the mobility system as a whole, rather than single products. In economic approach, it is difficult to calculate costs for social or environmental parameters. Assessment based on indicators reflects the technological aspect of the mobility system in a limited context. Meanwhile, MCDA rarely considers user behaviors, which play a highly important role in defining impacts of transport solutions.

In an effort to create a more comprehensive approach to evaluate different transport technologies for personal transportation, (Brunner, Hirz, Hirschberg, \& Fallast, 2018) introduces an objective evaluation using Weighted Traffic Performance Indices (WTPI). The WTPI is able to combine life cycle perspectives with user-related criteria to assess various forms of transport modes. Yet the study also does not consider the economic aspects of the transport options, as well as characteristics of goods transport.

This paper therefore addresses these gaps by 1) providing a review of common 
approaches to evaluate transport alternatives and evaluation criteria with an analysis of their application levels, and 2) proposing a framework for a holistic approach to analyze sustainability of transport alternatives.

This paper is structured as follows: the next session presents a short description of stateof-the-art approaches and their main methods as well as a description of evaluation criteria, followed by their application level analysis; the third session introduces a framework for a holistic evaluation that aims to support decision making process. Conclusion including further research directions comes in the last part.

\section{Review of Common Approaches to Sustainability Evaluation in the Transport Sector}

\subsection{Overview of the approaches}

The approaches included in this paper are based on the perspectives of life cycle, economic, multi-criteria decision analysis, and indicator-based assessment, respectively.

\subsubsection{Life cycle approach}

Started in 1970s, LCA has become a standardized methodology for the systematic assessment of environmental performance of any product or system, throughout its whole life cycle (ISO, 2006). Exemplary, a comparative vehicle LCA study is able to consider every possibly occurring necessary input and resulting output during different life cycle stages (i.e., production, operation and end-of-life treatment) and to directly assign these results to certain impact category over the entire life cycle of the product. The most typical and comprehensive focus frame is set from the beginning of production to end of life (from "cradle to grave"). This paper reviews two methods, namely product-based LCA and fleet-based LCA.

Product-based LCA method, or traditional LCA, can be used to compare the environmental impacts of vehicle technologies; however most studies are based on comparisons of single vehicles (Garcia \& Freire, 2017). Traditional LCA lacks a temporal dimension, thereby considerations of advances in technologies and the transient effects, which consider the fact that the substitution of an older technology by a newer one in a fleet happens gradually over time, are not included (Field, Kirchain, \& Clark, 2000). Scale and timing of adoption of new technologies can have an important influence on the result (Garcia \& Freire, 2017).

Fleet-based LCA method was first mentioned by (Field, Kirchain, \& Clark, 2000) as an answer to the aforementioned limitations of conventional LCAs. Fleet-based LCA is a combined approach, where especially during the use phase of a life cycle the focus is set on an entire fleet and its mobility behavior instead of focusing on a single vehicle. Therefore, fleet models and traffic flow simulations can be used to describe the stocks and flows associated with a class of product over time (Garcia \& Freire, 2017).

\subsubsection{Economic approach}

The two main methods in this approach are CBA and CEA.

CBA is a microeconomic method that translates the benefits and costs of projects into monetary values, by considering positive and negative impacts (Awasthi, Omrani, \& 
Gerber, 2018). Limitations of CBA are namely possible mismatch in information supply and demand, the generally constrained scope of benefits, and inconsideration of fundamental changes caused by transport investments to the quality and locations of stakeholders (International Transport Forum, 2017).

On the other hand, CEA is a technique that relates the costs of a program to its key outcomes or benefits (Cellini \& Kee, 2015). CEA is often used when it may be inappropriate to monetize the impacts (Awasthi, Omrani, \& Gerber, 2018), thus CEA requires that researchers have a concise measure of quality that is not itself measured in monetary units, therefore evaluation of quality is essential (Eger \& Wilsker, 2007).

\subsubsection{Multi-criteria decision analysis approach}

MCDA composes the framework for structuring decision problems and a set of methods for generating preferences among alternatives (Awasthi, Omrani, \& Gerber, 2018). MCDA is able to take into account the objectives of different interest groups or stakeholders (Marcharis \& Bernardini, 2015). There are three MCDA methods examined in this paper: value measurement, ideal-solution based, and outranking, adopted from (Awasthi, Omrani, \& Gerber, 2018).

Value measurement method aims to produce a means of associating a real value with each alternative, in order to construct a preference order of the alternatives in consistence with decision maker value weights (Barford \& Leleur, 2014). Alternatives are assessed by their total values, which represent an aggregated sum of criteria weights and each alternative value for these criteria (Awasthi, Omrani, \& Gerber, 2018). The most used techniques in the transport sector are Analytic Hierarchy Process (AHP), Analytical Network Process (ANP), Multi-Attribute Utility Theory (MAUT), Multi-Attribute Value Theory (MAVT), Simple Multi-Attribute Rating Technique (SMART), Simple MultiAttribute Rating Technique Exploiting Ranks (SMARTER). AHP and ANP are found to be dominant in use for transport projects, account for about one third MCDA-related studies in this field (Marcharis \& Bernardini, 2015).

Ideal-solution based method utilizes an ideal solution or a determined goal to evaluate alternatives. The ranking is made based on their closeness to the defined ideal solution, which is the point where all the criteria have been maximined or minimized (Awasthi, Omrani, \& Gerber, 2018). Typical techniques under this category include Technique for Ordered Preference by Similarity to Ideal Solution (TOPSIS), VIKOR, and Grey Relational Analysis (GRA).

Outranking method compares each pair of alternatives against every criteria to determine the extent to which an alternative would outrank the other. Two main techniques are Preference Ranking Organization Method for Enrichment Evaluation (PROMETHEE) and Elimination et Choice Translating Reality (ELECTRE) (Awasthi, Omrani, \& Gerber, 2018) (Marcharis \& Bernardini, 2015).

\subsubsection{Indicator-based approach}

For deciding a transport solution, there are objectives set by the decision makers, such as environment, social, and economic performance. Indicators or assessment criteria are identified in order to measure the sustainability of those objectives. Depending on context and level of the evaluation, various indicators can be 
defined. For example, in engineering projects, major indicators or assessment criteria can be health, safety, economic development, social equity, environmental quality, ecology, technical feasibility (Waheed, Khan, \& Veitch, 2009).

Focusing on quantitative indicator techniques, (Tao \& Hung, 2003) defines three categories of assessment indicator models, namely composite index models, multi-level index models and multi-dimension matrix models. Composite index model results in a single index, which indicates to which extent economic, social and environmental objectives are satisfied, for instance, ecological footprint or green gross national product. Multi-level index models utilize a set of indicators to reflect different goals and hierarchies. On the other hand, logic architectures are used to define interactions among various indicators in multi-dimension matrix models (Awasthi, Omrani, \& Gerber, 2018). Indicators can be associated to quantitative or qualitative performance data (Waheed, Khan, \& Veitch, 2009). In automotive industry, exemplary, the challenges for selecting suitable indicators to measure environmental performance are firstly to develop and evaluate appropriate normalized and functionally related indicators, and secondly to integrate indicators into the design and decision process using multi-objective approaches (Tam, 2002). Some techniques that can be found in this approach are linkage-based frameworks, such as Driving Force-Pressure-State-Exposure-EffectAction (Waheed, Khan, \& Veitch, 2009), Pressure-State-Response, Driving-Force-State response, and Driving-Force-Pressure-State-Impact-Response (Awasthi, Omrani, \& Gerber, 2018).

\subsection{Evaluation criteria}

Sustainable transport planning and management need to achieve an appropriate balance of environmental, economic, and social considerations (UNESCAP, 2015). Therefore, it is critical to select suitable evaluation criteria based on which decisions will be made. Even though several sustainablitiy assessment criteria applied in the transport sector exist in the literature, most of them only address environmental performance of the alternatives. (Olugu, Wong, \& Shaharoun, 2011) proposed a framework for green supply chain performance using 10 measures with 49 metrics for a forward chain, and 6 measures with 23 metrics for a backward one. These metrics reflect several aspects of a supply chain, such as environment, costs, management, quality, customer interest and satisfaction. On the other hand, (Arena, Azzone, \& Conte, 2013) utilized several dimensions and categories from the Global Reporting Initative (GRI) - the most wellestablished sustainability reporting guildlines in the world - and customized the list to make it more vehicle-related. They came up with 52 environmental and economic indicators covering each stage of the whole product lifecycle.

Perhaps one of the most well-structured frameworks for automotive sustainability assessment is presented by (Jasinski, Meredith, \& Kirwan, 2016), where a set of sustainabiliy assessment criteria was chosen from literature review and then refined by an interview study with 24 automotive experts representing academia, car manufactures, consultancies and non-governmental organisations. Through this process, 26 midpoint and 9 endpoint impact indicators, categorized into environmental, resource, social and economic impact groups, were established. This paper adopts the end-point indicators mentioned in (Jasinski, Meredith, \& Kirwan, 2016) as evaluation criteria (see Table 3). 


\subsection{Analysis of the methods and criteria}

Table 1 provides a summary of the main methods with their strengths and weaknesses extracted from different sources (Awasthi, Omrani, \& Gerber, 2018) (Field, Kirchain, \& Clark, 2000) (Garcia \& Freire, 2017) (Cellini \& Kee, 2015) (Eger \& Wilsker, 2007) (Marcharis \& Bernardini, 2015) (Meinrenken \& Lackner, 2015).

In addition, an analysis of the application level (system level and decision making level) of the studied methods can be seen in Table 2. Regarding the system level, the interactions between vehicles and the environment create boundaries for sustainability analysis. (Taiebat, Brown, R, Qu, \& Xu, 2018) defines four levels of increasing complexity: vehicle, transport system, urban system, and society. In this paper, we rank the system level of applying a certain method as Low (vehicle), Medium (transport or urban system), High (society), according to literature review. On the other hand, decision making levels follow the decision making pyramid (Srinivas, 2015), consisting of individual, community, city, national, global. This paper defines the decision making level as Low (individual), Medium (community or city), and High (national or global). Furthermore, we rank the application level of each evaluation critiera, using the defined system level and decision making level as shown in Table 3. From these analyses, the application levels of different evaluation methods and criteria are illustrated in Figure 1a and $1 \mathrm{~b}$.

Figure 1a shows that the two methods, which have widest application range, belong to MCDA approach, namely value measurement and ideal-solution based as they can be applied at any system or decision making level. Regardless of decision making level, the outranking MCDA is more suitable for Medium to High system level, while the economic approach can be utilized for less complex system level. The indicator-based method can be better used at higher hierarchy, ranging from Medium to High for both system and decision making levels. Traditional LCA, or product-based LCA, has been applied on the lower side of both levels, with Low system level and Low to Medium decision making level. Meanwhile, fleet-based LCA has higher performance, with system level being Low to Medium, as well as a Medium-to-High range for decision making. In a similar manner, Figure $1 \mathrm{~b}$ indicates that Climate Change and Human Health are most widely applicable for all system- or decision-making levels. The other social criteria, namely Quality of Life, is suitable for any level of decision making and higher system level. Dividends is one criteria that has best fit with low levels of both dimensions. Also in economic impact category, Taxes is appropriate to use at Medium to High decisionmaking level while covering all system levels. At the same time, Gross Value Added is applicable on a Low to Medium system hierarchy, while can be used for any decisionmaking levels. The other environmental criteria - Resource Depletion, Ecosystem Quality, and Impact on Biodiversity - locate from Medium to High on the decision making pyramid, however the former has Low to Medium system level while the other two can be applied at Medium to High system level. 
Table 1: Summary of the common approaches

\begin{tabular}{|c|c|c|c|}
\hline Approach & Method & Strength & Weakness \\
\hline \multirow[t]{2}{*}{ Life cycle } & $\begin{array}{l}\text { Product- } \\
\text { based } \\
\text { LCA }\end{array}$ & $\begin{array}{l}\text { Comparisons of alternative } \\
\text { products with comparable } \\
\text { functional units. }\end{array}$ & $\begin{array}{l}\text { Lack of temporal distribution of } \\
\text { emissions. } \\
\text { Social aspects are not included. }\end{array}$ \\
\hline & $\begin{array}{l}\text { Fleet-based } \\
\text { LCA }\end{array}$ & $\begin{array}{l}\text { Examination of all products in a } \\
\text { fleet, spatially and temporally. } \\
\text { Suitable for evaluating fleets with } \\
\text { under-developed products and } \\
\text { designs or in early use stage. }\end{array}$ & $\begin{array}{l}\text { More complex assessment. } \\
\text { Social aspects are not included. }\end{array}$ \\
\hline \multirow[t]{2}{*}{ Economic } & $\mathrm{CBA}$ & $\begin{array}{l}\text { Simple comparison of benefits } \\
\text { and costs of alternatives in terms } \\
\text { of monetary values. Dominant } \\
\text { method used in developing } \\
\text { countries. } \\
\text { Highly quantitative method. }\end{array}$ & $\begin{array}{l}\text { Uncertainties in estimations of } \\
\text { external and social costs (i.e. air } \\
\text { pollution, noise pollution, } \\
\text { accidents, congestions, fuel } \\
\text { costs). }\end{array}$ \\
\hline & CEA & $\begin{array}{l}\text { Comparison of costs and } \\
\text { emissions impacts when there are } \\
\text { non-monetary parameters. }\end{array}$ & $\begin{array}{l}\text { Mainly focus on economic } \\
\text { effects, neglect of ecological, } \\
\text { spatial or social aspects. }\end{array}$ \\
\hline \multirow[t]{3}{*}{ MCDA } & $\begin{array}{l}\text { Value } \\
\text { measure- } \\
\text { ment }\end{array}$ & $\begin{array}{l}\text { Ability to handle both quantitative } \\
\text { and qualitative criteria. }\end{array}$ & $\begin{array}{l}\text { The solutions are a tradeoff } \\
\text { among the multiple objectives, } \\
\text { not optimal. }\end{array}$ \\
\hline & $\begin{array}{l}\text { Ideal- } \\
\text { solution } \\
\text { based }\end{array}$ & $\begin{array}{l}\text { Quantitative by nature, easy to } \\
\text { integrate directly into Linear } \\
\text { Programming solvers. }\end{array}$ & $\begin{array}{l}\text { Uncertainties in assignment of } \\
\text { weights, determination of goals } \\
\text { and normalization of the } \\
\text { variables. }\end{array}$ \\
\hline & Outranking & $\begin{array}{l}\text { Provides a deep insight in the } \\
\text { problem structure and treatment } \\
\text { of decision makers uncertainties. }\end{array}$ & $\begin{array}{l}\text { Not suitable for comparing } \\
\text { many alternatives due to large } \\
\text { number of pairwise } \\
\text { comparisons. }\end{array}$ \\
\hline $\begin{array}{l}\text { Indicator- } \\
\text { based assess- } \\
\text { ment }\end{array}$ & $\begin{array}{l}\text { Indicator- } \\
\text { based }\end{array}$ & $\begin{array}{l}\text { Ability to take multi dimensions } \\
\text { (i.e., society, environment, } \\
\text { economy) into consideration. }\end{array}$ & $\begin{array}{l}\text { Risk in identifying right number } \\
\text { and type of indicators to } \\
\text { represent the social, economic } \\
\text { and environmental dimensions. }\end{array}$ \\
\hline
\end{tabular}

\subsection{Need for a holistic approach supporting sustainability evaluation in the transport sector}

Most existing literature present an analysis of different mobility options using one or a few methods, or a combination of them. In the transport sector, selection of the $\operatorname{method}(\mathrm{s})$ is often based on limited indicators, such as energy consumption and greenhouse gas emission (e.g., via $\mathrm{CO}_{2}$ equivalent). However, there are several other criteria, such as social or cost aspects, which should be considered but could be neglected, due to a lack of a holistic framework to guide the way. Such framework is proposed in the next session. 
Table 2: Analysis of the application levels of the methods

\begin{tabular}{|l|l|l|l|}
\hline Method & $\begin{array}{l}\text { System } \\
\text { Level }\end{array}$ & $\begin{array}{l}\text { Decision } \\
\text { Making } \\
\text { Level }\end{array}$ & Source \\
\hline $\begin{array}{l}\text { Product-based } \\
\text { LCA }\end{array}$ & Low & $\begin{array}{l}\text { Low to } \\
\text { Medium }\end{array}$ & $\begin{array}{l}\text { (Mierlo, Messagie, \& Rangaraju, 2017) (Agency, 2018) } \\
\text { (Petrauskiene, Skvarnaviciute, \& Dvarioniene, 2020) } \\
\text { (Bunner, Hirz, \& Fabian, 2014) (Hawkins, Singh, } \\
\text { Majeau-Bettez, \& Stromman, 2013) }\end{array}$ \\
\hline $\begin{array}{l}\text { Fleet-based } \\
\text { LCA }\end{array}$ & $\begin{array}{l}\text { Low to } \\
\text { Medium }\end{array}$ & $\begin{array}{l}\text { Medium to } \\
\text { High }\end{array}$ & $\begin{array}{l}\text { (Field, Kirchain, \& Clark, 2000) (Garcia \& Freire, 2017) } \\
\text { (Meinrenken \& Lackner, 2015) }\end{array}$ \\
\hline CBA & $\begin{array}{l}\text { Low to } \\
\text { Medium }\end{array}$ & Low to High & $\begin{array}{l}\text { (International Transport Forum, 2017) (Marcharis \& } \\
\text { Bernardini, 2015) }\end{array}$ \\
\hline CEA & $\begin{array}{l}\text { Low to } \\
\text { Medium }\end{array}$ & Low to High & $\begin{array}{l}\text { (Eger \& Wilsker, 2007) (Diez, Lopez-Lambas, Gonzalo, } \\
\text { \& Rojo, 2018) }\end{array}$ \\
\hline $\begin{array}{l}\text { Value } \\
\text { measurement }\end{array}$ & $\begin{array}{l}\text { Low to } \\
\text { High }\end{array}$ & Low to High & $\begin{array}{l}\text { (Longo, Medeossi, \& Padoano, 2015) (Awasthi, } \\
\text { Omrani, \& Gerber, 2018) (Marcharis \& Bernardini, } \\
\text { 2015) (Ramanathan, 2000) }\end{array}$ \\
\hline $\begin{array}{l}\text { Ideal-solution } \\
\text { based }\end{array}$ & $\begin{array}{l}\text { Low to } \\
\text { High }\end{array}$ & Low to High & $\begin{array}{l}\text { (Marcharis \& Bernardini, 2015) (Huang, Shuai, Sun, } \\
\text { Wang, \& Antwi, 2018) (Awasthi, Chauhan, \& Omrani, } \\
\text { 2011) }\end{array}$ \\
\hline Outranking & $\begin{array}{l}\text { Medium } \\
\text { to High }\end{array}$ & Low to High & $\begin{array}{l}\text { (Marcharis \& Bernardini, 2015) (Bojkovic, Anic, \& } \\
\text { Pejcic-Tarle, 2010) }\end{array}$ \\
\hline $\begin{array}{l}\text { Indicator- } \\
\text { based }\end{array}$ & $\begin{array}{l}\text { Medium } \\
\text { to High }\end{array}$ & $\begin{array}{l}\text { Medium to } \\
\text { High }\end{array}$ & $\begin{array}{l}\text { (Waheed, Khan, \& Veitch, 2009) (Hambling, } \\
\text { Weinstein, \& Slaney, 2011) (Lima, Lima, \& Silva, 2014) } \\
\text { (Dizdaroglu, 2017) (Kumar \& Anbanandam, 2019) }\end{array}$ \\
\hline
\end{tabular}

Table 3: Analysis of the application levels of the criteria (evaluation criteria adopted from (Jasinski, Meredith, \& Kirwan, 2016))

\begin{tabular}{|l|l|l|l|l|}
\hline Impact category & Criteria & Code & System Level & Decision Making Level \\
\hline Environmental (E) & Climate change & E-CC & Low to High & Low to High \\
\cline { 2 - 5 } & Ecosystem quality & E-EQ & Medium to High & Medium to High \\
\cline { 2 - 5 } & Impact on biodiversity & E-IB & Medium to High & Medium to High \\
\cline { 2 - 5 } & Resource depletion & E-RD & Low to Medium & Medium to High \\
\hline Social (S) & Human health & S-HH & Low to High & Low to High \\
\cline { 2 - 5 } & Quality of life & S-QL & Medium to High & Low to High \\
\hline Economic (EC) & Gross value added & EC-GVA & Low to Medium & Low to High \\
\cline { 2 - 5 } & Dividends & EC-D & Low & Low \\
\cline { 2 - 5 } & Taxes & EC-T & Low to High & Medium to High \\
\hline
\end{tabular}
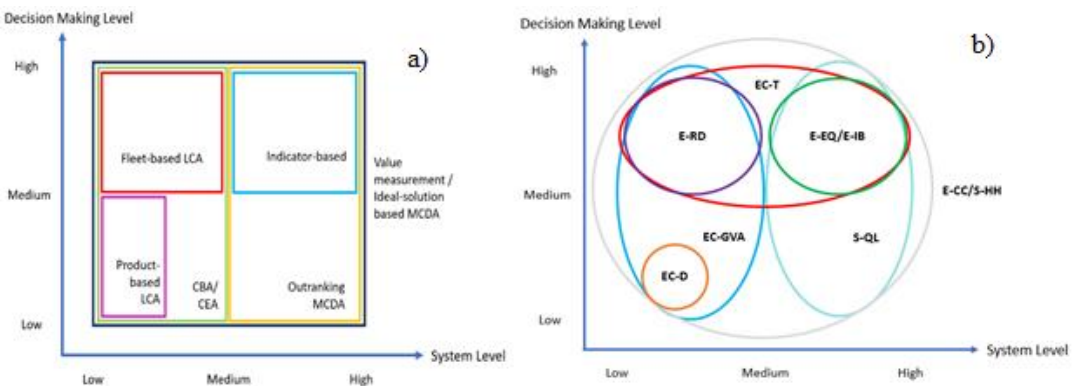

Figure 1a, b: Application levels of selected evaluation methods (a) and evaluation criteria (b) in the transport sector 


\section{Towards a Holistic Decision Support Framework for Sustainable Transport Alternatives}

\subsection{Proposal of a holistic framework}

This paper presents a six-step framework for holistic evaluation of transport alternatives, as can be seen in Figure 2. Each step is described in the following paragraphs.

In the first step, system level and decision-making level of the assessment are defined. After that, a set of criteria for comparing the alternatives are identified. Based on the definitions in step 1, suitable analysis approach(es) and method(s) are selected. Methods are chosen according to their ability to provide comprehensive and comparable values for the alternatives under each criterion. Once the methods are set, they require data inputs for calculations and analysis. Data collection therefore comes as the third step. Each method asks for different data inputs within a certain system boundary. For example, LCA includes life cycle inventory where all inputs and outputs are quantified through the product life cycle. Meanwhile, benefits and impacts are translated into economic values in CBA and CEA. MCDA, for instance, collects information from stakeholders via different focus groups. Indicator-based assessment requires data representing the linkages of the system. Enabling a holistic evaluation and comparison, an important part of data collection represents the setup of a database with technical characteristics of different transport systems (e.g. energy consumption, vehicle occupancy, vehicle dimensions, maximum speed, driving range or suitability for different weather conditions).

In the next step, data processing can involve simulations or analyse sets of quantitative or qualitative data. The outcome of this step provides values associated with the criteria for each alternative. Based on these values, the alternatives are compared. As a result, the alternatives are ranked according to the criteria. It is worth mentioning that the ranking is not absolute, but can serve to show how the alternatives perform under certain criteria. The goal of evaluation is to provide decision makers a holistic view of the transport alternatives, thereby deciding based on their priority.

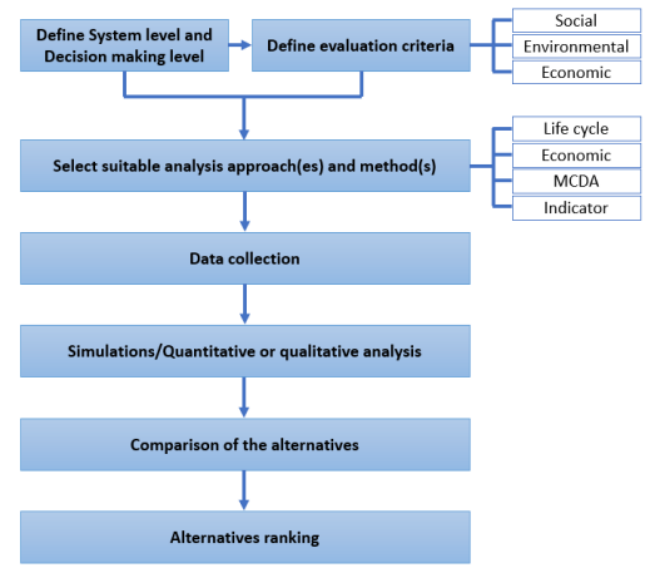

Figure 2: Framework for a bolistic decision support 
The framework is designed with a broad range of applications in mind. It is suitable for decision making of transport projects at any level. Decision making processes consist of several stages, as Figure 3 indicates (Hussung, 2017). In this context, the introduced framework can be utilized in the middle of the process, after alternatives have been identified.

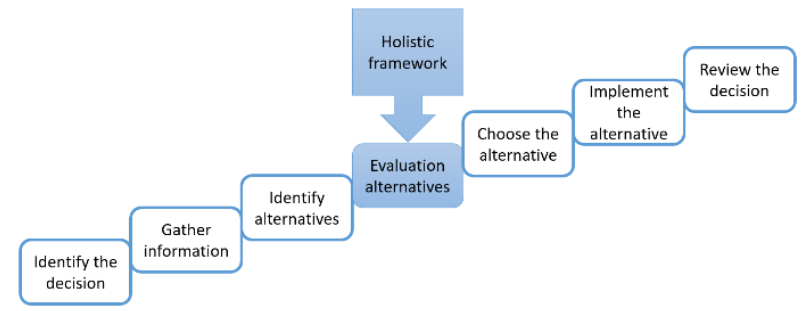

Figure 3: Holistic framework applied in the decision-making process

\subsection{Future development}

Beyond the scope of this paper, the framework can serve as a backbone of a decision-making tool for mobility projects, aiming for both passenger and freight transport. Since every evaluation method requires plenty of inputs and analysis, combining several methods under one umbrella involves several steps.

To be specific, the next steps to develop this framework are:

- Formulate the selection process of suitable evaluation methods as well as data processing.

- Build a database of technical characteristics of different transport systems.

- Establish a holistic decision-making tool for transport alternatives.

- Validate the tool with real-life case studies.

\section{Conclusions}

The paper presents a review of common approaches for sustainability evaluation in the field of transport. Application levels of the methods and evaluation criteria are depicted based on their system level and decision making level. The paper also proposes a framework for a holistic evaluation of transport alternatives with the aim to assist decision making processes for projects in the transport sector. Future research is planned in order to realize the framework in the form of a useful decision making tool, as well as to validate the framework by applying it in real-life cases.

\section{References}

Agency, E. E. (2018). Electric vehicles from life cycle and circular economy perspectives TERM Report. Luxembourg: EEA.

Arena, M., Azzone, G., \& Conte, A. (2013). A streamlined LCA framework to support early decision making in vehicle development. Journal of Cleaner Production, 41, 105-113.

Awasthi, A., Chauhan, S. S., \& Omrani, H. (2011). Application of fuzzy TOPSIS in evaluating sustainable transportation systems. Expert Systems with Applications, 38, 12270-12280. 
Awasthi, A., Omrani, H., \& Gerber, P. (2018). Investigating ideal-solution based multicriteria decision making techniques for sustainability evaluation of urban mobility projects. Transportation Research Part A, 116, 247-259.

Barford, M. B., \& Leleur, S. (2014). Multi-criteria decision analysis for use in transport decision making. DTU Lyngby: DTU Transport.

Bojkovic, N., Anic, I., \& Pejcic-Tarle, S. (2010). One solution for cross-country transport-sustainability evaluation using a modified ELECTRE method. Ecological Economics, 69, 1176-1186.

Brunner, H., Hirz, M., Hirschberg, W., \& Fallast, K. (2018). Evaluation of various means of transport for urban areas. Energy, Sustainability and Society, 8(9).

Bunner, H., Hirz, M., \& Fabian, J. (2014). Life Cycle Assessment of Urban Mobility. FISITA World Congress. Maastricht.

Cellini, S. R., \& Kee, J. E. (2015). Cost-effectiveness and cost-benefit analysis. In Handbook of practical program evaluation, fourth edition. Jossey-Bass.

Diez, J. M., Lopez-Lambas, M. E., Gonzalo, H., \& Rojo, M. (2018). Methodology for assessing the cost effectiveness of Sustainable Urban Mobility Plans (SUMPs). The case of the city of Burgos. Journal of Transport Geography, 68, 22-30.

Dizdaroglu, D. (2017). The Role of Indicator-Based Sustainability Assessment in Policy and the DecisionMaking Process: A Review and Outlook. Sustainability, $9(6)$.

EEA, E. E. (2019). Greenhouse gas emissions from transport in Europe. Copenhagen: EEA.

Eger, R. J., \& Wilsker, A. L. (2007). Cost Effectiveness Analysis and Transportation: Practices, Problems, and Proposals. Public Budgeting and Finance, 27(1), 104-116.

eurostat. (2019). Energy, transport and environment statistics. Imprimeries Bietlot Frères.

Field, F., Kirchain, R., \& Clark, J. (200). Life-cycle assessment and temporal distributions of emisson Developing a fleet-based analysis. Journal of Industrial Ecology, 4(2), 71-91.

Garcia, R., \& Freire, F. (2017). A review of fleet-based life-cycle approaches focusing on energy and environmental impacts of vehicles. Renewable and Sustainable Energy Reviews, 79, 935-945.

Hambling, T., Weinstein, P., \& Slaney, D. (2011). A Review of Frameworks for Developing Environmental Health Indicators for Climate Change and Health. International Journal of Environmental Research and Public Health, 8.

Hawkins, T. R., Singh, B., Majeau-Bettez, G., \& Stromman, A. H. (2013). Comparative Environmental Life Cycle Assessment of Conventional and Electric Vehicles. Journal of Industrial Ecology, 17(1), 53-64.

Huang, W., Shuai, B., Sun, Y., Wang, Y., \& Antwi, E. (2018). Using entropy-TOPSIS method to evaluate urban rail transit systemoperation performance: The China case. Transportation Research Part A, 111, 292-303.

Hussung, T. (2017, 2 10). 7 Steps of the Decision Making Process. (Concordia University Saint-Paul) Retrieved 2 26, 2020, from https://online.csp.edu/blog/business/decision-making-process

IEA, I. E. (2017). Energy Technology Perspectives. OECD/IEA.

Intergovernmental Panel on Climate Change, I. (2014). Climate Change 2014. Cambridge: Cambridge University Press.

International Transport Forum, I. (2017). Quantifying the socio-economic benefits of transport. Paris: OECD Publising.

ISO, I. O. (2006, 7). ISO 14040:2006 Environmental management — Life cycle assessment — Principles and framework. (ISO) Retrieved 27,2020 , from https://www.iso.org/standard/37456.html

Jasinski, D., Meredith, J., \& Kirwan, K. (2016). A comprehensive framework for automotive sustainability assessment. Journal of Cleaner Production, 135, 1034-1044.

Kumar, A., \& Anbanandam, R. (2019). Development of social sustainability index for freight transportation system. Journal of Cleaner Production, 210, 77-92.

Lima, J. P., Lima, R. d., \& Silva, A. N. (2014). Evaluation and selection of alternatives for the promotion of sustainable urban mobility. Procedia - Social and Behavioral Sciences, 162, 408-418.

Longo, G., Medeossi, G., \& Padoano, E. (2015). Multi-Criteria analysis to support mobility management at a university campus. Transportation Research Procedia, 5, 175-185.

Marcharis, C., \& Bernardini, A. (2015). Reviewing the use of Multi-Criteria Decision Analysis for the evaluation of transport projects: Time for a multi-actor approach. Transport Policy, 37, 177-186.

Meinrenken, C. J., \& Lackner, K. S. (2015). Fleet view of electrified transportation reveals smaller potential to reduce GHG emissions. Applied Energy, 138, 393-403. 
Messagie, M., Boureima, F., Matheys, J., Sergeant, N., Turcksin, L., Macharis, C., \& Van Mierlo, J. (2010). Life Cycle Assessment of conventional and alternative small passenger vehicles in Belgium. IEEE Vebicle Power and Propulsion Conference. Lille.

Mierlo, J. V., Messagie, M., \& Rangaraju, S. (2017). Comparative environmental assessment of alternative fueled vehicles using a life cycle assessment. Transportation Research Procedia, 25, 3435-3445.

Olugu, E. U., Wong, K. Y., \& Shaharoun, A. M. (2011). Development of key performance measures for the automobile green supply chain. Resources, Conservation and Recycling, 55, 567-579.

Petrauskiene, K., Skvarnaviciute, M., \& Dvarioniene, J. (2020). Comparative environmental life cycle assessment of electric and conventional vehicles in Lithuania. Journal of Cleaner Production, 246(119042).

Programme, U. N. (2018). Emissions Gap Report. Nairobi: UNEP.

Ramanathan, R. (2000). A holistic approach to compare energy e\$ciencies of dilerent transport modes. Energy Policy, 28, 743-747.

Srinivas, H. (2015, 4). GDRC Research Output E-003. (Global Development Research Center) Retrieved 2 18, 2020, from http://www.gdrc.org/decision/pyramid.html

Taiebat, M., Brown, A. L., R, S. H., Qu, S., \& Xu, M. (2018). A Review on Energy, Environmental, and Sustainability Implications of Connected and Automated Vehicles. Environmental Science and Technology, 52, 11449-11465.

Tam, E. K. (2002). Challenges in using environmental indicators for measuring sustainability practices. Journal of Environmental Engineering and Science, 1(6), 417-425.

Tao, C. C., \& Hung, C. C. (2003). A comparative approach of the quantitative models for sustainable transportation. Journal of the Eastern Asia Society for Transportation Studies, 5, 3329-3344.

UNESCAP. (2015, 7 9). United Nations ESCAP. Retrieved 5 1, 2020, from https://www.unescap.org/sites/default/files/2_Concept $\% 20$ of $\% 20$ Sustainable\%20Transport_ES CAP.pdf

Waheed, B., Khan, F., \& Veitch, B. (2009). Linkage-Based Frameworks for Sustainability Assessment: Making a Case for Driving Force-Pressure-State-Exposure-Effect-Action (DPSEEA) Frameworks. Sustainability, 1, 441-463. 